\title{
Comparative Evaluation of Smear Layer Formation of WaveOne Gold, Protaper Gold and Manual files: an In vitro SEM Study
}

\author{
Mostafa Ali \\ MSc Student, Endodontic Department, Faculty of Dentistry, Misr International University, Cairo, \\ Egypt. E-mail:drmostafalii@gmail.com
}

Salma El Ashry

Professor of Endodontics, Endodontic Department, Faculty of Dentistry, Ain Shams University Cairo, Egypt. E-mail: ashry68@yahoo.com

\author{
Amira Galal Ismail \\ Researcher of Endodontics, Restorative and Dental Material Department, National Research Centre, \\ 33 El Buhouth St., 12622 Dokki, Giza, Egypt. E-mail: amiragalal@gmail.com
}

Received: 25 April 2020 / Accepted 20 June 2020 / Publication date: 30 June 2020

\begin{abstract}
Aim: The purpose of this study is to compare smear layer formation between reciprocating single file system WaveOne Gold, rotational multiple file system Protaper Gold and manual file.

Material and Methods: Forty eight lower central incisors with single straight canals were selected to assess smear layer formation after instrumentation using manual file, WaveOne Gold and Protaper Gold. Samples were divided into three groups $(n=16)$ according to the instrument used for preparation. They were divided into two halves. All specimens were coded for identification under the environmental scanning electron microscope at 500x for each group, then the most representable area of each third of the root was selected and magnified at 2000x. Evaluations were recorded for the smear layer in the three levels of the canal (coronal, middle and apical) by means of numerical evaluation scale described by Hulssman. The data were subjected to the non-parametric KruskalWallis test. $\mathrm{P}$ values were computed and compared with the $\mathrm{P}=0.05$. Results: All types of instrumentation produced a significant amount of smear layer in the three levels of the canal. Regarding the coronal and the apical third there were no statistically significant differences between the three tested groups. In the middle third there was no statistically significant difference between the WaveOne Gold group and the manual file group or the Protaper Gold group. However there was a statistically significant difference between the manual file group and the Protaper Gold group.

Conclusion: Smear layer was formed in the three tested groups at different levels of the canals regardless of the kinematics of the instrument with the manual file group revealing the least amount.
\end{abstract}

Keywords: WaveOne Gold, Protaper Gold, Reciprocation, continuous rotation

\section{Introduction}

Shaping, cleaning and sealing of the root canal system is mandatory for successful root canal treatment. Its main objective is to eliminate the microorganisms from the root canals and prevent its recontamination after obturation (Siqueira, 2003).

Despite the type of the instrument used to prepare the root canal, a smear layer is formed in the instrumented areas in which it consists of organic and inorganic parts that include remnants of pulp tissues, dentin chips, microorganism and necrotic materials. Smear layer can cover the root canal wall, occlude the dentinal tubules and prevent root canal filling material and used medication to be in direct contact with root dentin thus preventing intimate seal and bonding (Violich and Chandler, 2010).

There is a great tendency among clinicians to use single file systems because they reduce the time of the preparation. Furthermore, reciprocation extends the life span of the nickel titanium (NiTi) file, improves their resistance to cyclic fatigue and doesn't reduce their cutting efficiency (Bürklein et al., 2019).

Corresponding Author: Amira Galal Ismail, Researcher of Endodontics, Restorative and Dental Material Department, National Research Centre, 33 El Buhouth St., 12622 Dokki, Giza, Egypt. E-mail: amiragalal@gmail.com 
WaveOne Gold is a new reciprocating single file NiTi file system introduced as a modified version of WaveOne and developed with proprietary advanced metallurgy through heat treatment called Gold-wire. WaveOne Gold has a significant gold color, and modified offset parallelogram cross sectional design (Özyürek, 2016).

Protaper Gold is a new rotary NiTi file system introduced as a modified version of the famous Protaper Universal and developed with proprietary advanced metallurgy through the heat treatment. Protaper Gold has all the features as the well-known Protaper Universal including the convex triangular cross section design, progressive taper and non-cutting tip (Elnaghy and Elsaka, 2016).

Thus, the aim of the present study was to compare between WaveOne Gold reciprocating single file system and Protaper Gold multi file rotational system.

\section{Materials and Methods}

\section{Sample selection:}

Forty eight extracted human mandibular central incisors with mature apices were collected, cleaned from calculus and debris. They were placed in full concentration of $\mathrm{NaOCl}$ for one hour to remove soft debris and then stored in sterile saline to avoid dehydration. Buccal and proximal radiograph were taken to each tooth to confirm single root anatomy.

Access cavities were prepared in all teeth using diamond burs. Root canals were checked for patency. The working length was determined by passing k-file size \# 10 through the apical foramen once and withdraw it $1 \mathrm{~mm}$. To ensure that all teeth have the same tooth length, the incisal edge of all teeth were flattened using tapered stone with round end. Working length was then adjusted to $19 \mathrm{~mm}$ in all canals to eliminate confounders which might affect the results.

The 48 incisors teeth were randomly divided into three groups according to the instrument used in preparation as follows:

Group 1: Manual file ( $\mathrm{n}=16)$.

Group 2: WaveOne Gold ( $\mathrm{n}=16)$.

Group 3: Protaper Gold ( $\mathrm{n}=16)$.

\section{Mechanical Preparations:}

Sodium hypochlorite was used as an irrigant in the three groups. In each sample, a total of $3 \mathrm{~mL}$ of sodium hypochlorite was used between files in manual file and Protaper Gold group, and between the pecking sequences in WaveOne Gold group. A 30-G side vented irrigation needle was placed in the canal without resistance but not deeper than the predetermined working length minus $1 \mathrm{~mm}$.

\section{Manual file:}

Teeth were prepared using manual stainless steel $\mathrm{k}$ file using step back technique. Starting by inserting file \# 10 to the full working length followed by file \# 15, 20 and then finally file \# 25 .

\section{WaveOne Gold:}

Teeth were prepared with WaveOne Gold primary instrument (25/.07) using the X-Smart Plus (Dentsply Maillefer) motor that was adjusted for reciprocating motion according to the manufacturer's instructions. The instrument was used in an in and out motion until the working length was achieved.

\section{Protaper Gold:}

Teeth were prepared using Protaper Gold according to the manufacturer's instructions. S1 was introduced into the canal until the depth of the working length was reached then S2 was used exactly as for the S1. Then, S2, F1 and F2 were used in a non-brushing action until working length is reached.

\section{SEM Evaluation:}

Smear layer was evaluated in teeth with the use of the environmental scanning electron microscope. After irrigation and dryness with paper point, the coronal part of the teeth was decoronated horizontally at the cemento enamel junction. The roots were sectioned longitudinally by making two grooves on both mesial and distal surfaces by using a diamond disc without penetrating the canals. 
The roots were split into two halves with a chisel and mallet. All specimens were then coded for identification. The samples were mounted on metallic disc to be examined under the environmental scanning electron microscope at 500x magnification for each group, then the most representable area of each third of the root was selected and magnified at 2000x.

Evaluations were recorded for the smear layer in the three areas of the canal (coronal, middle and apical) by means of numerical evaluation scale described by Hulssman et al. (1997). The score were the following:

Score 1: no smear layer, orifice of dentinal tubules patent

Score 2: small amount of smear layer, some open dentinal tubule

Score 3: homogenous smear layer along almost the entire canal wall, only very few open dentinal tubules

Score 4: the entire root canal wall covered with a homogenous smear layer, no open dentinal tubules

Score 5: a thick, homogeneous smear layer covering the entire root canal wall

\section{Statistical Analysis}

The data established for scoring the smear layer were recorded and analyzed statically in each group. Owing to the ordinal nature of the scores, the data were subjected to the non-parametric Kruskal-Wallis test. $\mathrm{P}$ values were computed and compared with the $\mathrm{P}=0.05$.

\section{Results}

Regarding the coronal third and apical third, no statistically significant differences were apparent between the three instrumentation methods $(\mathrm{P}=0.249),(\mathrm{P}=0.137)$. Regarding the middle third there was no statistically significant difference between the WaveOne Gold group either with the manual file group $(\mathrm{P}=0.055)$ or the Protaper Gold group $(\mathrm{P}=0.244)$. However there was a statistically significant difference between the manual file group and the Protaper Gold group in which manual file recorded cleaner surface in term of smear layer formation ( $\mathrm{P}=0.046)$. Table (1), Figures (1), (2), (3).

Table 1: Smear layer score percentage in coronal, middle and apical thirds in the three tested groups

\begin{tabular}{|c|c|c|c|c|c|c|c|c|c|c|}
\hline \multirow{3}{*}{ Section } & \multirow{3}{*}{ Score } & \multicolumn{6}{|c|}{ Groups } & & \multirow{2}{*}{\multicolumn{2}{|c|}{ P-value }} \\
\hline & & \multicolumn{2}{|c|}{ Manual } & \multicolumn{2}{|c|}{ Protaper Gold } & \multicolumn{2}{|c|}{ WaveOne Gold } & & & \\
\hline & & $\mathbf{N}$ & $\%$ & $\mathbf{N}$ & $\%$ & $\mathbf{N}$ & $\%$ & & \multirow{4}{*}{0.249} & \\
\hline \multirow{3}{*}{ Coronal } & 2 & 6 & 75.00 & 2 & 25.00 & 5 & 62.50 & & & \\
\hline & 3 & 2 & 25.00 & 5 & 62.50 & 3 & 37.50 & & & \\
\hline & 4 & 0 & 0.00 & 1 & 12.50 & 0 & 0.00 & & & \\
\hline \multirow{4}{*}{ Middle } & 2 & 4 & 50.00 & 0 & 0.00 & 0 & 0.00 & \multirow{4}{*}{$0.023^{*}$} & M\&P & $0.046^{*}$ \\
\hline & 3 & 4 & 50.00 & 4 & 50.00 & 7 & 87.50 & & M\&W & 0.055 \\
\hline & 4 & 0 & 0.00 & 3 & 37.50 & 1 & 12.50 & & & \\
\hline & 5 & 0 & 0.00 & 1 & 12.50 & 0 & 0.00 & & P\&W & 0.244 \\
\hline \multirow{4}{*}{ Apical } & 2 & 1 & 12.50 & 0 & 0.00 & 0 & 0.00 & & \multirow{4}{*}{0.137} & \\
\hline & 3 & 5 & 62.50 & 1 & 12.50 & 5 & 62.50 & & & \\
\hline & 4 & 2 & 25.00 & 4 & 50.00 & 1 & 12.50 & & & \\
\hline & 5 & 0 & 0.00 & 3 & 37.50 & 2 & 25.00 & & & \\
\hline \multirow{4}{*}{ Total } & 2 & 11 & 45.83 & 2 & 8.33 & 5 & 20.83 & \multirow{4}{*}{$0.006^{*}$} & M\&P & $0.003 *$ \\
\hline & 3 & 11 & 45.83 & 10 & 41.67 & 15 & 62.50 & & M\&W & 0.182 \\
\hline & 4 & 2 & 8.33 & 8 & 33.33 & 2 & 8.33 & & & \\
\hline & 5 & 0 & 0.00 & 4 & 16.67 & 2 & 8.33 & & P\&W & 0.088 \\
\hline
\end{tabular}




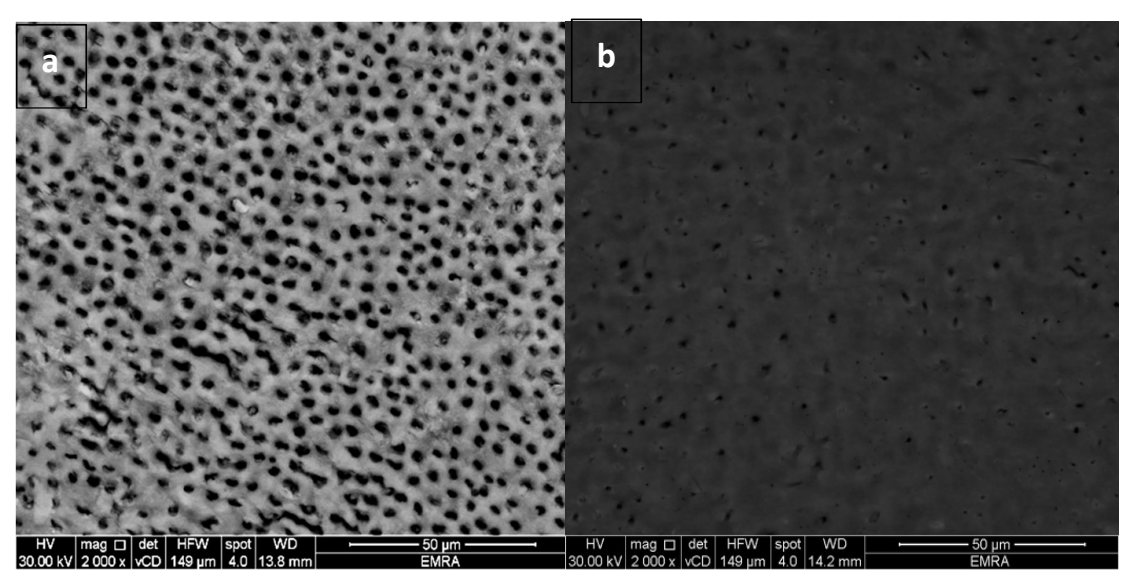

Fig. 1: SEM photograph showing the smear layer formation of manual file group at the (a) middle third: score 2, (b) apical third: score 3

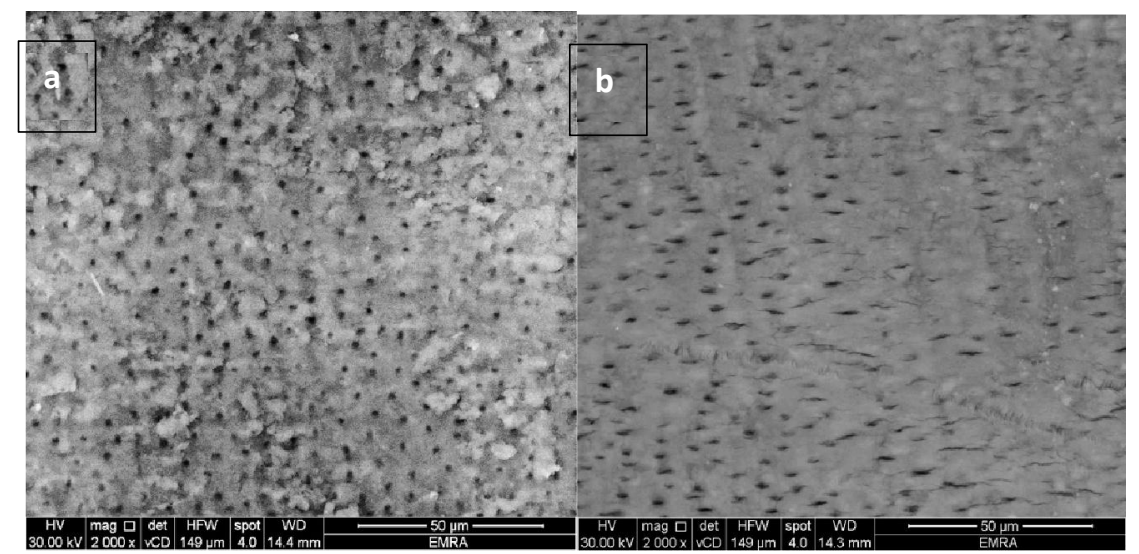

Fig. 2: SEM photograph showing the smear layer formation of Protaper Gold group at the (a) middle third: score 3, (b) apical third: score 4

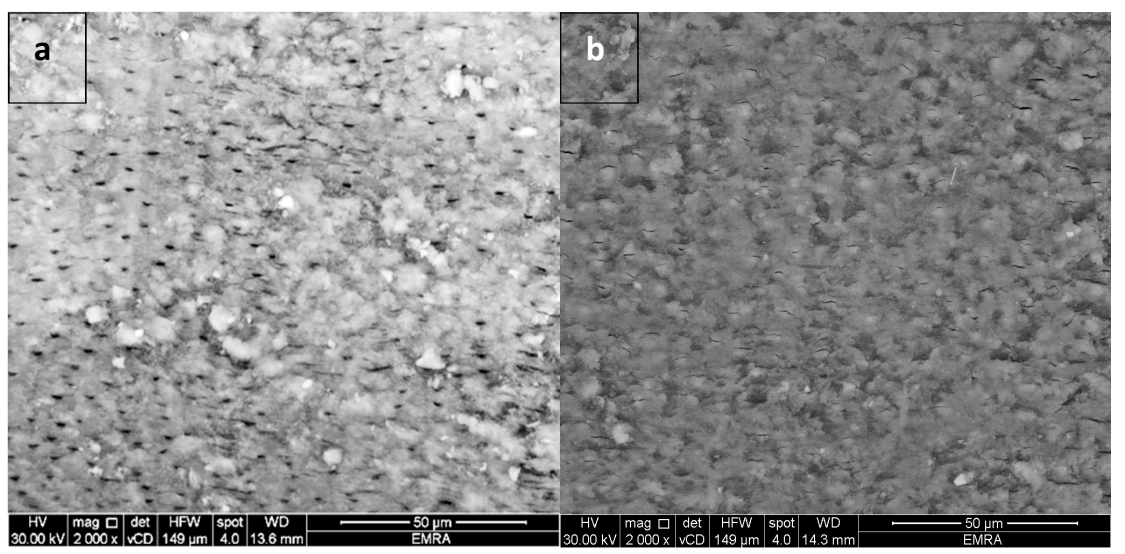

Fig. 3: SEM photograph showing the smear layer formation of WaveOne group at the (a) middle third: score 4, (b) apical third: score 5 


\section{Discussion}

The objective of root canal preparation is to clean and shape the root canal system to eliminate necrotic materials, microorganisms, and pulp tissue remnants to facilitate the placement of a permanent root canal filling material.

Despite the type of the instrument used to prepare the root canal, a smear layer is formed in the instrumented areas in which it consists of organic and inorganic parts that include remnants of pulp tissues, dentin chips, microorganism and necrotic materials. Smear layer can cover the root canal wall, occlude the dentinal tubules and prevent root canal filling material and used medication to be in direct contact with root dentin thus preventing intimate seal and bonding (Mader et al., 1984).

Although it's recommended to use a chelating agent such as EDTA in combination with sodium hypochlorite during root canal preparation, EDTA was not used in this study and only sodium hypochlorite was used as an irrigant in the three tested groups. EDTA solution is commonly used for the removal of the formed smear layer, therefore creating a clean field for better disinfection of the canal and letting the other irrignt to reach the dentinal tubules. The objective of this study is to assess the amount of smear layer formed by the different instrumentation technique, therefore EDTA was not used as it aids in smear layer removal (Bürklein et al., 2011).

In the present study clean smear layer portion was assessed on the basis of numerical evaluation score for smear layer by SEM evaluation of the coronal, middle and apical thirds of the canals (Hulsmann et al., 1997).

The result of the study showed that all instrumentation techniques used resulted in smear layer formation in different areas of the canals which is in accordance with the majority of previous studies (Schäfer and Zapke, 2000; Ahlquist et al., 2001; Schäfer and Lohmann, 2002). All groups have been shown to leave uninstrumented multiple areas in the canal wall. Moreover, the presence of the smear layer might be considered as an indicator of the cleaning efficiency of the instrument used in this study.

When using manual, rotary and reciprocating motion, no significant difference in term of smear layer formation was found in the coronal and apical thirds of the canals between the three groups. Nonetheless, the manual group showed significantly lesser amount of smear layer when compared with the Protaper Gold group in the middle third of the canal. While there was no significant difference between the WaveOne gold and both the manual and Protaper Gold group in the middle third of the canal. According to endodontic literature, rotary instrumentation of root canal produce thicker smear layer than manual instrumentation (Zan et al., 2016 and Ruddle, 2016).

In some manual group specimens groove marks are present in the canal surfaces. These distinct grooves may be attributed to the inherent stiffness of the stainless steel manual file. One author described instrument groove both after manual and rotary instrumentation (Bürklein et al., 2019).

On average, more effective cleanliness was obtained in the coronal third followed by the middle third then the apical third which showed the highest smear layer formation score regardless of the instrument used. This finding is in agreement with many previous studies. Also this finding maybe more important than the result of the comparison between the three file system in which the apical part scored with highest amount of smear layer, it means that microorganisms remain in the apical parts and further measures should be taken to deliver the antibacterial solution in the apical part to prevent reinfection of the canal and the subsequent need for retreatment.

The design feature of the instrument may affect directly the cleansing efficiency of the instrument. Protaper Gold has a modified triangular cross section presenting no active cutting edge with a neutral rake angle (Elnaghy and Elsaka, 2016). A positive rake angle permits the instrument to cut more aggressively whereas a negative or neutral rake angle will only grind the root canal wall. Also instruments with fixed taper allow dentin chips to be accumulated in the coronal part of the file in addition it can cause screw in effect in which the file is pulled into the apical direction and removing excessive amounts of dentin. The greater taper of the Protaper Gold 0.08 (Elnaghy and Elsaka, 2016) might be the reason for increased smear layer formation score especially in the apical third.

In this experiment we have more than different variables present, file design, file taper, file kinematics and the number of file used. Therefore we cannot connect just one variable to the experiment result while ignoring the other variables. WaveOne Gold has a parallelogram cross section 
(Bürklein et al., 2019; Özyürek, 2016) which permit the file to engage the dentin in only one point along the canal wall providing a space around the instrument for better debris accumulation and then better coronal debris removal, this unique design could be one reason for the better performance

The technique of smear layer scoring by scanning electron microscopes is subjective and may provide incomplete readings. The magnification power is critical by using low magnification to view wider areas and observing the root canal wall and the need to use the high magnification to see the details of the specimens. The magnification of 500x was selected because it gives a wider view for the whole area of the root but when an area of interest was present, a magnification of 2000x was used for better details and more information.

\section{Conclusion}

Under the conditions of this study, smear layer formation is an inevitable consequence of root canal preparation. Both WaveOne Gold and Protaper Gold produced comparable amount of smear layer with the least amount formed in the manual group.

\section{References}

Ahlquist, M., O. Henningsson, K. Hultenby and J. Ohlin, 2001. The effectiveness of manual and rotary techniques in the cleaning of root canals: a scanning electron microscopy study. International Endodontic journal, 34(7):533-7.

Bürklein, S., C. Hiller, M. Huda and E. Schäfer, 2011. Shaping ability and cleaning effectiveness of Mtwo versus coated and uncoated EasyShape instruments in severely curved root canals of extracted teeth. International Endodontic Journal, 44(5):447-57.

Bürklein, S., S. Flüch and E. Schäfer, 2019. Shaping ability of reciprocating single-file systems in severely curved canals: WaveOne and Reciproc versus WaveOne Gold and Reciproc blue. Odontology, 107(1):96-102.

Elnaghy, A.M. and S.E. Elsaka, 2016. Mechanical properties of ProTaper Gold nickel-titanium rotary instruments. International Endodontic Journal, 49(11):1073-8.

Hülsmann, M., C. Rümmelin and F. Schäfers, 1997. Root canal cleanliness after preparation with different endodontic handpieces and hand instruments: a comparative SEM investigation. Journal of Endodontics, 23(5):301-6.

Mader, C.L., J.C. Baumgartner and D.D. Peters, 1984. Scanning electron microscopic investigation of the smeared layer on root canal walls. Journal of Endodontics, 10(10):477-83.

Özyürek, T., 2016. Cyclic fatigue resistance of Reciproc, WaveOne, and WaveOne Gold nickeltitanium instruments. Journal of Endodontics, 42(10):1536-9.

Ruddle, C.J., 2016. Single-file shaping technique: Achieving a gold medal result. Dent Today. 35(1):1-7.

Schäfer, E. and D. Lohmann, 2002. Efficiency of rotary nickel-titanium FlexMaster instruments compared with stainless steel hand K-Flexofile- Part 2. Cleaning effectiveness and instrumentation results in severely curved root canals of extracted teeth. International Endodontic Journal, 35(6):514-21.

Schäfer, E. and K. Zapke, 2000. A comparative scanning electron microscopic investigation of the efficacy of manual and automated instrumentation of root canals. Journal of Endodontics, 26(11):660-4.

Siqueira, Jr J.F., 2003. Microbial causes of endodontic flare-ups. International Endodontic Journal, 36(7):453-63.

Violich, D.R. and N.P. Chandler, 2010. The smear layer in endodontics-a review. International endodontic journal, 43(1):2-15.

Zan, R., T. Tunç, I. Hubbezoglu and Z. Sümer, 2016. Apical extrusion of intracanal biofilm using ProTaper Gold, WaveOne Gold, Twisted File Adaptive, One Shape new generation and K3XF. European Endodontic Journal, 1(1):3. 